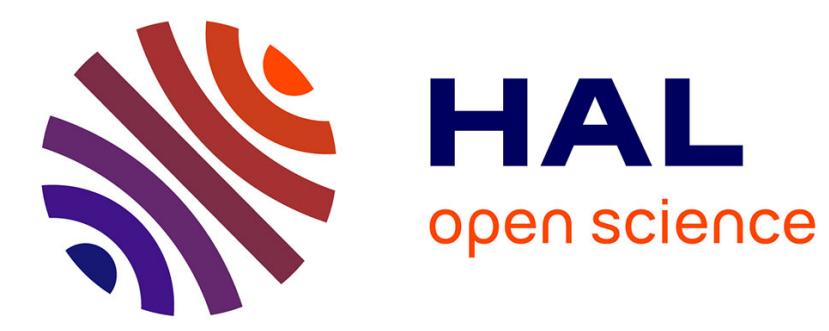

\title{
Size effect assessment by Weibull's approach and the coupled criterion
}

\author{
Aurélien Doitrand, Ronan Henry, Tanja Lube, Sylvain Meille
}

\section{To cite this version:}

Aurélien Doitrand, Ronan Henry, Tanja Lube, Sylvain Meille. Size effect assessment by Weibull's approach and the coupled criterion. Engineering Fracture Mechanics, 2021, 256, pp.107979. 10.1016/j.engfracmech.2021.107979 . hal-03394411

HAL Id: hal-03394411

https://hal.science/hal-03394411

Submitted on 22 Oct 2021

HAL is a multi-disciplinary open access archive for the deposit and dissemination of scientific research documents, whether they are published or not. The documents may come from teaching and research institutions in France or abroad, or from public or private research centers.
L'archive ouverte pluridisciplinaire HAL, est destinée au dépôt et à la diffusion de documents scientifiques de niveau recherche, publiés ou non, émanant des établissements d'enseignement et de recherche français ou étrangers, des laboratoires publics ou privés. 


\title{
Size effect assessment by Weibull's approach and the coupled criterion
}

\author{
Aurelien Doitrand ${ }^{\mathrm{a}, *}$, Ronan Henry ${ }^{\mathrm{a}}$, Tanja Lube ${ }^{\mathrm{b}}$, Sylvain Meille $^{\mathrm{a}}$ \\ ${ }^{a}$ Univ Lyon, INSA Lyon, UCBL, CNRS, MATEIS, UMR5510, 69621 Villeurbanne, France \\ ${ }^{b}$ Department of Materials Science, University of Leoben, Leoben, Austria
}

\begin{abstract}
We evaluate Weibull's approach and the coupled criterion (CC) ability to reproduce bending failure stress variations as a function of specimen size in two porous materials, namely gypsum or zinc oxyde. Whereas both approaches well reproduce the size effect in gypsum specimens, only the $\mathrm{CC}$ succeeds in correctly predicting the failure stress variation for $\mathrm{ZnO}$ specimens. We thus question the basis assumption of increasing critical flaw size with increasing specimen size associated to Weibull's approach. Employing the CC to predict prematurate specimen failure initiating from a critical pore, we determine a relation between the failure force decrease and the corresponding possible critical pore size range. For the three tested gypsum types, we estimate the critical pore size range to lie around 50-250 microns, not retrieving increasing critical pore size with increasing specimen size, as assumed in Weibull's approach, but rather a constant critical pore size range for all specimens.

Keywords: Strength; porosity/flaw; size effect; Four-point bending; Coupled criterion ;
\end{abstract}

\section{Nomenclature}

$a, b:$ constants

$d:$ pore diameter

$E$ : Young's modulus

$F_{c}$ : Failure force

$G_{c}$ : Critical energy release rate

$G_{i n c}$ : Incremental energy release rate

${ }^{*}$ Corresponding author

Email address: aurelien.doitrand@insa-lyon.fr (Aurelien Doitrand) 
$h:$ Specimen width

$h_{d}$ : Pore center to specimen edge distance

$K_{I c}:$ Critical stress intensity factor

$l:$ Crack length

$l_{c}:$ Initiation crack length

$l_{\text {mat }}$ : Material characteristic length

$L_{\text {span }}$ : Four point bending lower span distance

$l_{\text {span }}:$ Four point bending upper span distance

$m$ : Weibull's modulus

$P_{F}$ : Weibull's model probability of failure

$t$ : Specimen thickness

$U_{c}$ : Initiation prescribed displacement

$V$ : Specimen volume

$V^{\prime}$ : Specimen volume sollicitated under tension

$V_{E F F}$ : Specimen effective volume

$V_{0}$ : Weibull's model constant

$v_{p}$ : Pore volume fraction

$W:$ Potential energy

$x, y:$ Cartesian coordinates

$\nu$ : Poisson's ratio

$\rho:$ density

$\sigma$ : opening stress

$\sigma_{c}:$ tensile strength

$\sigma_{\max }:$ maximum stress under bending

$\sigma_{0}:$ Weibull's model constant

CC : Coupled Criterion

LEFM : Linear Elastic Fracture Mechanics 


\section{Introduction}

Increasing bending strength (i.e., the maximum bending stress in the specimen at failure) corresponding to decreasing specimen size is usually observed under bending. The bending strength dependency on the specimen dimensions is called "size effect", which describes the nominal failure stress variation as a function of a characteristic structure dimension. This topic was extensively studied by Bazant et al. [1, 2, 3, 4]. They proposed to combine the theory of plasticity and Linear Elastic Fracture Mechanics (LEFM) to reproduce deterministic size effects. It was made possible since through the combination of both approaches, a characteristic length emerges: $\frac{E G_{c}}{\sigma_{y}^{2}}$, where $E$ is the material Young's modulus, $G_{c}$ the critical energy release rate and $\sigma_{y}$ the yield limit.

An explanation of size effect based on the weakest link theory was earlier introduced by Weibull [5, 6, 7]. This is a statistical description of failure relying on the fact that it occurs due to the presence of a critical flaw inside the material in an area sollicitated under tension. Moreover, it assumes that the smaller the specimen, the smaller the probability to encounter a large critical flaw. Based on these assumptions, the failure probability is expressed as a function of the specimen volume sollicitated under tension and the maximum local stress level. Weibull's approach was widely used to predict the strength of ceramic materials [8, 9, 10]. It was also shown that other statistical distribution functions could lead to a better fit of the experimentally observed size effect [11], since Weibull's description may predict either weaker [8] or stronger [12] size effects than observed experimentally. Even if it is constructed from mechanical considerations, this approach remains an empirical statistical description that is not based on a mechanical description of failure. In particular, this approach does not contain any material characteristic length [1].

An approach from which emerges a characteristic length is the coupled criterion (CC). It was introduced by Leguillon [13] in order to predict crack initiation, which is not achieved employing classical LEFM because of the assumption of a pre-existing crack. The CC consists in combining stress and energy requirements to determine the initiation crack length and loading. A characteristic length emerges from coupling both conditions, which allows deterministic size effects to be assessed. The CC was successfully employed to describe size

effects in composites [13, 14, 15, 16], in notched or plain concrete specimens [17], in specimens 
with blunt notches [18, 19, 20] or holes [18, 20, 21, 22, 23, 24]. The size effect assessment by the CC offered an alternative explanation to the statistical approach. Leguillon et al. [25] even combined the CC and Weibull's approach in order to explain the difference between the bending and tensile strengths.

This work is dedicated to assess the ability of Weibull's approach and the CC to reproduce failure stress variation as a function of specimen size in gypsum and $\mathrm{ZnO}$ specimens under four-point bending. Experiments are presented in Section 3. In Section 4, we recall both approaches for size effect assessment, which is presented in Section 5. In section 6, we use the $\mathrm{CC}$ in order to predict crack initiation from a critical pore and estimate the possible critical pore range in the tested specimens.

\section{Experiments}

The size effect analysis is based on two series of experimental tests on gypsum [26] and zinc oxide $(\mathrm{ZnO})$ taken from [8].

\subsection{Bending tests on gypsum}

Three types of gypsum with different pore fraction $v_{p}$, density $\rho$, Young's modulus $E$ and Poisson's ratio $\nu$ are studied [27, 28, 29]. They also exhibit different critical energy release rates $G_{c}$ and tensile strengths $\sigma_{c}$ [26] and are referred to as $\gamma$-gypsum, $\alpha$-gypsum and $\beta$-gypsum. Gypsum samples are prepared by hydration of hemihydrate. Hemihydrate only exists in two forms, alpha or beta, leading to alpha and beta gypsum after hydration. The sample referred to as gamma gypsum is process by hydration of alpha hemihydrate with a low amount of water. Their properties are given in Tab. 1 .

\begin{tabular}{|c|c|c|c|c|c|c|}
\hline gypsum type & $v_{p}$ & $\rho\left(\mathrm{g} / \mathrm{cm}^{3}\right)$ & $E(\mathrm{GPa})$ & $\nu$ & $G_{c}\left(\mathrm{~J} / \mathrm{m}^{2}\right)$ & $\sigma_{c}(\mathrm{MPa})$ \\
\hline$\gamma$ & $15 \%$ & $1.94 \pm 0.03$ & $38 \pm 1$ & 0.21 & $3.5 \pm 1.5$ & $12.7 \pm 2$ \\
\hline$\alpha$ & $30 \%$ & $1.59 \pm 0.03$ & $16 \pm 0.5$ & 0.21 & $7.5 \pm 1.5$ & $9.9 \pm 1.5$ \\
\hline$\beta$ & $50 \%$ & $1.03 \pm 0.03$ & $3.8 \pm 0.5$ & 0.21 & $2.5 \pm 2$ & $3.3 \pm 1$ \\
\hline
\end{tabular}

Table 1: Properties of the three types of gypsum.

Four-point bending tests are performed at ambient temperature on several specimens of each gypsum type exhibiting different widths in order to assess a possible size effect. Two bending apparatus respectively with $\left(L_{\text {span }}=90.5 \mathrm{~mm}, l_{\text {span }}=30 \mathrm{~mm}\right)$ and $\left(L_{\text {span }}=35 \mathrm{~mm}\right.$, 
$l_{\text {span }}=10 \mathrm{~mm}$ ) lower and upper span distance, are used depending on the specimen width. The $\alpha^{-}, \beta$ - and $\gamma$-gypsum specimen dimensions and corresponding failure forces $\left(F_{c}\right)$ and bending stresses $\left(\sigma_{\max }\right)$ are given respectively in Tabs. 2, 3 and 4 . The relation between $\sigma_{\max }$ and $F_{c}$ is derived from Euler-Bernoulli beam theory:

$$
F_{c}=\frac{2}{3} \frac{t h^{2} \sigma_{\max }}{\left(L_{\text {span }}-l_{\text {span }}\right)}
$$

where $t$ and $h$ are respectively the specimen thickness and width.

\begin{tabular}{|c|c|c|c|}
\hline Number of specimens $\alpha$ & 10 & 8 & 21 \\
\hline$h(\mathrm{~mm})$ & $4.01 \pm 0.15$ & $5.23 \pm 0.15$ & $10.05 \pm 0.33$ \\
\hline$t(\mathrm{~mm})$ & $3.03 \pm 0.07$ & $10.17 \pm 0.32$ & $10.25 \pm 0.38$ \\
\hline$\rho\left(\mathrm{g} / \mathrm{cm}^{3}\right)$ & $1.59 \pm 0.05$ & $1.61 \pm 0.02$ & $1.58 \pm 0.07$ \\
\hline$F_{c}(\mathrm{~N})$ & $16.25 \pm 1.18$ & $37.39 \pm 2.48$ & $122.75 \pm 16.05$ \\
\hline$\sigma_{\max }(\mathrm{MPa})$ & $12.29 \pm 1.19$ & $12.15 \pm 1.36$ & $10.66 \pm 1.32$ \\
\hline$L_{\text {span }}(\mathrm{mm})$ & 35.00 & 90.50 & 90.50 \\
\hline$l_{\text {span }}(\mathrm{mm})$ & 10.00 & 30.00 & 30.00 \\
\hline
\end{tabular}

Table 2: Dimensions, failure force $F_{c}$ and bending stress $\sigma_{\max }$ corresponding to $\alpha$-gypsum specimens.

\begin{tabular}{|c|c|c|c|c|}
\hline Number of specimens $\beta$ & 11 & 9 & 8 & 21 \\
\hline$h(\mathrm{~mm})$ & $2.63 \pm 0.2$ & $4.14 \pm 0.11$ & $5.32 \pm 0.06$ & $10.27 \pm 0.4$ \\
\hline$t(\mathrm{~mm})$ & $7.15 \pm 0.76$ & $2.92 \pm 0.03$ & $10.02 \pm 0.26$ & $10.65 \pm 0.33$ \\
\hline$\rho\left(\mathrm{g} / \mathrm{cm}^{3}\right)$ & $1.02 \pm 0.03$ & $1.05 \pm 0.02$ & $1.05 \pm 0.04$ & $1.05 \pm 0.03$ \\
\hline$F_{c}(\mathrm{~N})$ & $4.62 \pm 1.39$ & $4.87 \pm 0.60$ & $11.11 \pm 0.43$ & $37.49 \pm 9.58$ \\
\hline$\sigma_{\max }(\mathrm{MPa})$ & $3.48 \pm 0.76$ & $3.47 \pm 0.45$ & $3.16 \pm 0.54$ & $3.22 \pm 0.84$ \\
\hline$L_{\text {span }}(\mathrm{mm})$ & 35.00 & 35.00 & 90.50 & 90.50 \\
\hline$l_{\text {span }}(\mathrm{mm})$ & 10.00 & 10.00 & 30.00 & 30.00 \\
\hline
\end{tabular}

Table 3: Dimensions, failure force $F_{c}$ and bending stress $\sigma_{\max }$ corresponding to $\beta$-gypsum specimens.

\begin{tabular}{|c|c|c|c|c|}
\hline Number of specimens $\gamma$ & 2 & 9 & 5 & 17 \\
\hline$h(\mathrm{~mm})$ & $2.18 \pm 0.01$ & $4.17 \pm 0.17$ & $5.04 \pm 0.19$ & $10.13 \pm 0.36$ \\
\hline$t(\mathrm{~mm})$ & $8.36 \pm 1.29$ & $3.00 \pm 0.08$ & $10.15 \pm 0.22$ & $9.83 \pm 0.33$ \\
\hline$\rho\left(\mathrm{g} / \mathrm{cm}^{3}\right)$ & $1.94 \pm 0.01$ & $1.94 \pm 0.04$ & $1.93 \pm 0.04$ & $1.95 \pm 0.04$ \\
\hline$F_{c}(\mathrm{~N})$ & $18.12 \pm 3.47$ & $25.04 \pm 6.34$ & $35.31 \pm 6.72$ & $144.25 \pm 25.26$ \\
\hline$\sigma_{\max }(\mathrm{MPa})$ & $16.94 \pm 0.74$ & $16.43 \pm 2.06$ & $12.82 \pm 2.18$ & $12.94 \pm 1.84$ \\
\hline$L_{\text {span }}(\mathrm{mm})$ & 35.00 & 35.00 & 90.50 & 90.50 \\
\hline$l_{\text {span }}(\mathrm{mm})$ & 10.00 & 10.00 & 30.00 & 30.00 \\
\hline
\end{tabular}

Table 4: Dimensions, failure force $F_{c}$ and bending stress $\sigma_{\max }$ corresponding to $\gamma$-gypsum specimens.

The measured failure stress decreases with increasing specimen width for the three types of gypsum, hence highlighting a size effect. Therefore the bending strength cannot be considered 


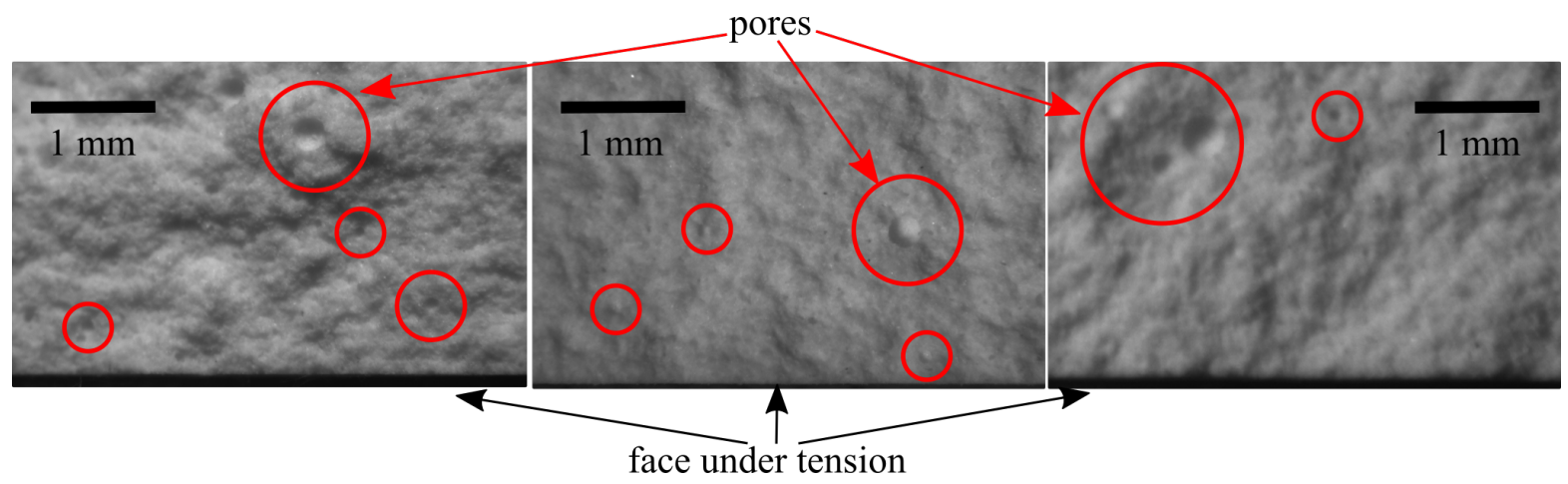

Figure 1: Typical fracture surface of $\beta$-gypsum specimen containing spherical pores of different sizes and located at different positions along the specimen width.

as an intrinsic material property since it depends on the specimen size, as mentioned in [25]. Fig 1 shows typical fracture surfaces observed in $\beta$-gypsum specimens. The fracture surfaces highlight the presence of spherical isolated pores, located at different position along the specimen width and with different sizes. In some cases, a cluster of several pores may also be observed.

\subsection{Bending tests on $\mathrm{ZnO}$}

Previously performed experiments on $\mathrm{ZnO}$ specimens under four-point bending and exhibiting three different widths are also analyzed [8]. The material behavior is linear elastic until brittle failure. The material properties are $E=110 \mathrm{GPa}, \nu=0.35, \sigma_{c}=100 \mathrm{MPa}$ and $K_{I c}=1.27 \mathrm{MPa} \cdot \mathrm{m}^{0.5}\left(G_{c}=12.9 \mathrm{~J} / \mathrm{m}^{2}\right)[30$. The material contains about 5 vol $\%$ porosity. The specimen and apparatus dimensions are summarized in Tab. 5 as well as the failure force and stress. It can be noted that data corresponding to the largest specimens were reported from [8], whereas the data corresponding to the two other sets of specimens (two first columns in Tab. 5) were calculated from the individual (respectively 100 and 109 tested specimens) experimental results. It can be observed that almost no size effect is highlighted since the failure stress lies around $100 \mathrm{MPa}$ with some scattering that is larger for smaller specimens. 


\begin{tabular}{|c|c|c|c|}
\hline Number of specimens & 100 & 109 & 42 \\
\hline$h(\mathrm{~mm})$ & $1.50 \pm 0.03$ & $3.00 \pm 0.02$ & $6.00 \pm 0.02$ \\
\hline$t(\mathrm{~mm})$ & $2.01 \pm 0.02$ & $3.98 \pm 0.04$ & $8.00 \pm 0.04$ \\
\hline$F_{c}(\mathrm{~N})$ & $33.70 \pm 5.70$ & $122.8 \pm 16.70$ & $666.0 \pm 42.0$ \\
\hline$\sigma_{\max }(\mathrm{MPa})$ & $95.70 \pm 15.80$ & $101.9 \pm 12.90$ & $104.0 \pm 6.50$ \\
\hline$L_{\text {span }}(\mathrm{mm})$ & 13.00 & 40.00 & 60.00 \\
\hline$l_{\text {span }}(\mathrm{mm})$ & 4.33 & 20.00 & 30.00 \\
\hline
\end{tabular}

Table 5: Dimensions, failure force $F_{c}$ and bending stress $\sigma_{\max }$ corresponding to $\mathrm{ZnO}$ specimens.

\section{Approaches for size effect assessment}

\subsection{Weibull's model}

Weibull's model is based on the theory of the weakest link and provides a statistical description of brittle failure. It is based on the assumption that failure is initiated by the most critical flaw in a specimen, and that the larger the specimen, the larger the probability to encounter a large critical flaw and vice-versa. It also takes into account the stress level to which the specimen is subjected, the failure probability being larger for larger stress levels. Based on these considerations, an empirical model giving the failure probability of a specimen of volume $V=h t L_{\text {span }}$ undergoing a stress gradient $\sigma$ is derived:

$$
P_{F}(\sigma, V)=1-\exp \left(-\left(\frac{\sigma_{\max }}{\sigma_{0}}\right)^{m} \frac{V_{E F F}}{V_{0}}\right)
$$

where $V_{E F F}=\int_{V^{\prime}}\left(\frac{\sigma}{\sigma_{\max }}\right)^{m} d V$ with $V^{\prime}$ the volume sollicitated under tension. $m$ is called the Weibull's modulus and $\sigma_{0}$ and $V_{0}$ are fitting parameters so that for $V_{E F F}=V_{0}$ and $\sigma_{\max }=\sigma_{0}$, the failure probability is $1-\frac{1}{e}$. In the case of four-point bending, $V^{\prime}$ corresponds to the specimen volume delimited by $[0, t] \times\left[0, \frac{h}{2}\right] \times\left[-\frac{L_{\text {span }}}{2}, \frac{L_{\text {span }}}{2}\right]$, therefore the effective volume is:

$$
V_{E F F}=\frac{V\left(m \frac{l_{\text {span }}}{L_{\text {span }}}+1\right)}{2(m+1)^{2}}
$$

The Weibull's modulus is representative of failure stress data scattering. For given specimen dimensions, wide (resp. narrow) failure stress distributions are obtained for small (resp. large) $m$ values. The determination of Weibull's modulus can be obtained with the following approach:

i) The specimens are sorted by increasing failure stress $\sigma_{i}$, 
ii) Each specimen is given a failure probability $P_{i}\left(\sigma_{i}\right)=\frac{i-0.5}{N}$, where $N$ is the specimen number,

iii) $m$ is calculated as the slope of a linear fitting of the curve representing $\ln \left(\ln \left(\frac{1}{1-P_{i}}\right)\right)$ as a function of $\ln \left(\sigma_{i}\right)$.

We illustrate the Weibull's modulus determination in Fig. 2 for the $21 \alpha$ - gypsum specimens having a $h \approx 10 \mathrm{~mm}$ width. Given Eq. (2) and two samples having different effective volumes $\left(V_{E F F}^{(1)}\right.$ and $\left.V_{E F F}^{(2)}\right)$, the failure stress of specimen $2\left(\sigma_{\max }^{(2)}\right)$ required to have the same failure probability is, knowing the failure stress of specimen $1\left(\sigma_{\max }^{(1)}\right)$ :

$$
\sigma_{\max }^{(2)}=\sigma_{\max }^{(1)}\left(\frac{V_{E F F}^{(1)}}{V_{E F F}^{(2)}}\right)^{\frac{1}{m}}
$$

The size effect arises from Eq. (4) from which it can be deduced that the smaller the specimen, the larger the failure stress. From this relation we can also observe that failure stress exhibits a linear variation (slope $-\frac{1}{m}$ ) as a function of the specimen effective volume in a log-log representation. Finally, the validity of the Weibull's approach can be assessed by first identifying the Weibull's modulus on a given set of specimens with similar dimensions. Then, a blind prediction of the failure forces (or stresses) of other specimens with different dimensions can be performed and compared to the failure forces and stresses measured ex-

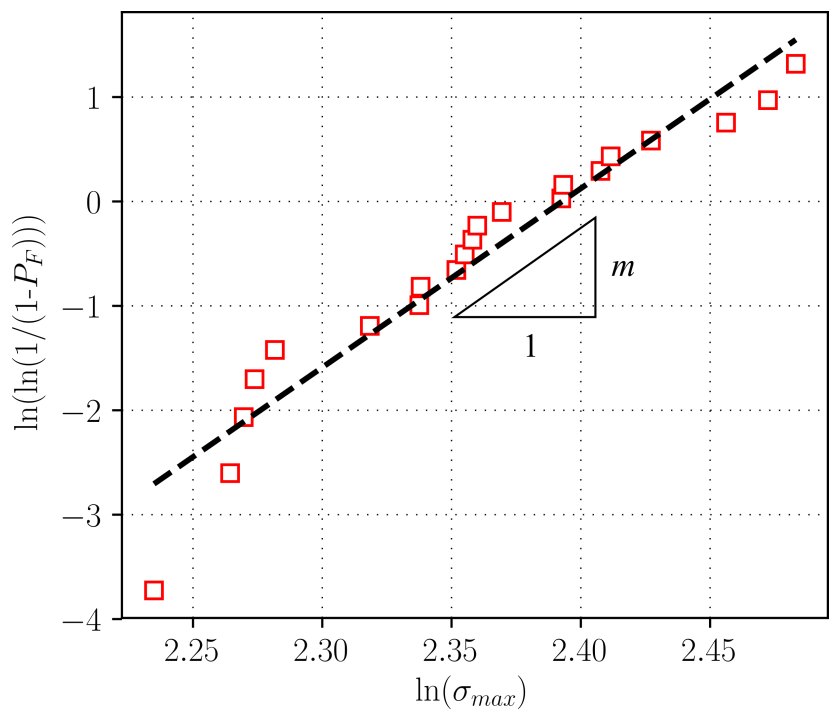

Figure 2: Example of determination of the Weibull's modulus m for $\alpha$-gypsum specimens. 
perimentally. In the sequel, the Weibull's modulus identification is performed on specimens exhibiting $h \approx 10 \mathrm{~mm}$ width for $\alpha-, \beta$ - and $\gamma$-gypsum specimens (largest number of tested specimens) and for specimens having $h \approx 1.5 \mathrm{~mm}$ width for $\mathrm{ZnO}$ specimens.

\subsection{The coupled criterion}

The coupled criterion has been developed in order to study crack initiation. It is founded on the fact that the nucleation of a crack requires two separate conditions to be simultaneously fulfilled. The first condition results from a balance of the kinetic, potential and crack surface creation energies between the states before and after crack initiation. It states that the potential energy released due to crack initiation must be larger than the energy required for the crack surface creation. The second condition formulates that the stress state must be larger than the material tensile strength. The initiation loading is determined as the minimum loading for which both conditions are simultaneously fulfilled, which also allows the determination of the initiation crack length. Its application and numerical implementation in the case of four-point bending is detailed in [26, 31]. The application of the CC showed that for specimens large enough compared to the material characteristic length $\left(l_{m a t}=\frac{E G_{c}}{\left(1-\nu^{2}\right) \sigma_{c}^{2}}\right)$, the bending strength is close to the tensile strength, otherwise it depends on the specimen width and the material elastic $(E, \nu)$ and fracture $\left(G_{c}, \sigma_{c}\right)$ properties. An analytical expression of the bending strength involving these parameters was derived in [26]:

$$
\frac{\sigma_{\max }}{\sigma_{c}}=\frac{\left(\frac{h}{l_{\text {mat }}}\right)^{a}+1}{\left(\frac{h}{l_{\text {mat }}}\right)^{a}+b}
$$

where $a=0.884$ and $b=0.179$. This expression can be used for any material under linear elasticity and small deformation assumption in the range $\frac{h}{l_{\text {mat }}}>0.1$. Therefore, knowing the specimen dimensions and material properties, it provides an analytical estimate of the failure stress $\sigma_{\max }$ an thus of the corresponding failure force $F_{c}$ based on the CC. An analytical expression of the initiation length can also be derived [26].

\subsection{The coupled criterion for a specimen containing a pore}

The CC may also be applied following Weibull's approach reasoning that failure occurs from the most critical flaw in the specimen. In the sequel, we make the following assumptions: 
- The critical flaw is a pore with diameter $d$ and located at a distance $h_{d}$ from the surface undergoing tension (cf. Fig. 3a)

- The pore is located within the specimen volume undergoing tension and lies within the specimen middle plane,

- The pore is entirely located within the specimen, i.e. we do not consider surface flaws.

The presence of a pore has an influence on the stress variation along the specimen width [32]. Indeed, it induces two local stress concentrations around the pore, in addition to the stress concentration at the specimen surface induced by the specimen bending. These stress concentrators are priviledged crack initiation locations, we thus study three crack initiation scenarii in the sequel:

1) A crack initiates from the hole, on the side of the specimen surface undergoing tension,

2) A crack initiates from the hole, on the side opposite to the specimen surface undergoing tension,

3) A crack initiates from the specimen surface undergoing tension.

It can be noted that other scenarii may happen such as the simultaneous initiation of more than one cracks at several stress concentrators, which are not studied herein.

Similarly to the case without a pore, crack initiation requires both stress and energy criteria to be simultaneously fulfilled. The energy condition compares the incremental energy release rate $G_{i n c}$, defined as the ratio between the potential energy released by crack initiation



(a)



(b)

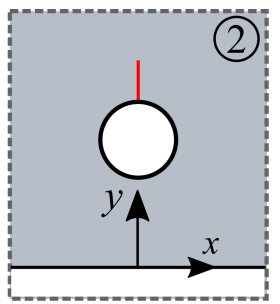

(c)

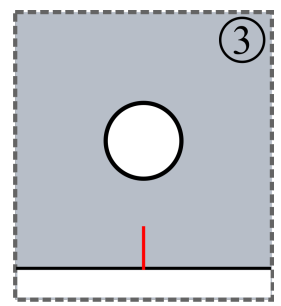

(d)

Figure 3: a) Four-point bending specimen containing a pore. Crack initiation scenarii b) at the hole on the side of the specimen edge under tension, c) at the hole on the side opposite to the specimen edge under tension and d) at the specimen edge under tension. 
$(-\Delta W=W(0)-W(l))$ and the crack extension $(l)$, to the material critical energy release rate $G_{c}$. The stress condition compares the opening stress to the material strength all along the initiation crack path. These conditions writes:

$$
\left\{\begin{array}{l}
G_{i n c}\left(l_{c}, U_{c}\right)=-\frac{\Delta W\left(l_{c}\right)}{l_{c}}=G_{c} \\
\sigma\left(l, U_{c}\right) \geqslant \sigma_{c} \forall l \leqslant l_{c}
\end{array}\right.
$$

It can be noted that in Eq. (6), the initiation length and loading levels are a priori unknown. They can be determined by solving the system, which reverts to determining the minimum imposed displacement (and the corresponding crack length) for which both conditions are fulfilled.

Under the assumption of linear elasticity and small deformations, the CC implementation

requires the calculation of i) the stress field along the crack path before crack initiation and ii) the potential energy release as a function of the crack length. The former is determined based on a 2D FE calculation (plane strain assumption) without crack and the latter is calculated while successively doubling the mesh nodes along the crack path to vary the crack length. The main expected differences compared to 3D calculations is the failure force level, since initiation crack lengths obtained in 2D are representative of 3D initiation crack extensions in the specimen middle plane [21, 33]. The mesh size along the crack path can be choosen based on the knowledge that the initiation length is a fraction of the material characteristic length $l_{\text {mat }}$ [34]. In practice, a $\frac{l_{\text {mat }}}{100}$ minimum mesh size is adopted, typically resulting in meshes containing $\approx 5000$ degrees of freedom. For a given configuration (i=1, 2 or 3 , cf. Fig. 3bd), the CC allows computing the initiation crack length $l_{c}^{(i)}$ and imposed displacement $U_{c}^{(i)}$. The crack initiation scenario which is likely to happen is the one minimizing the imposed displacement among the three studied scenarii. A comparison of the different scenarii and the corresponding CC solutions is presented in Section 6 .

\section{Size effect}

Size effect assessment using either Weibull's approach or the CC is evaluated for gypsum and $\mathrm{ZnO}$ specimens. 


\subsection{Gypsum specimens}

The failure force corresponding to all the specimens ( $c f$. Tab 2 24 4 ) are computed using the CC or Weibull's approach. For each type of gypsum, the Weibull's modulus is identified based on the set of largest specimens ( $c f$. Tab. 2 24 4 ) following the procedure described in Section 4. The obtained values are:

- $\alpha$-gypsum: $m_{\alpha}=17$

- $\beta$-gypsum: $m_{\beta}=9$

- $\gamma$-gypsum: $m_{\gamma}=16$

The failure forces predicted by Weibull's approach for the other specimens ( $c f$. Tab. 24 4 ) are then obtained using Eqs. (4) and (1). The failure forces obtained using the CC or Weibull's approach are shown in Figs. 4 and 5. First, it can be observed that both approaches give

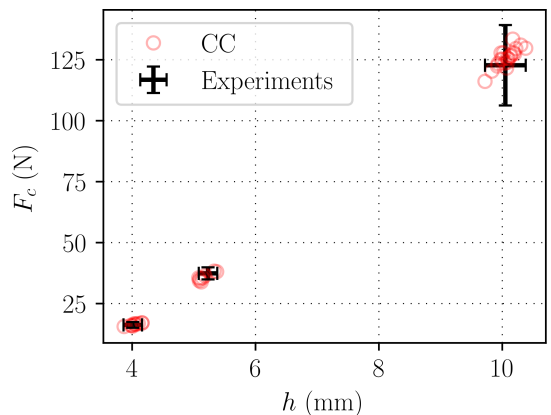

(a)

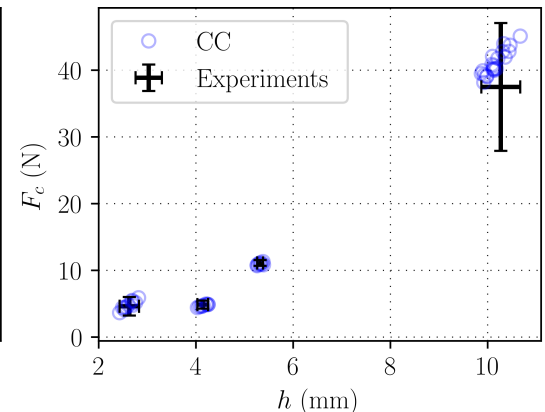

(b)



(c)

Figure 4: Failure forces obtained with the $\mathrm{CC}$ as a function of specimen width for a) $\alpha-$, b) $\beta-$ and c) $\gamma-$ gypsum.

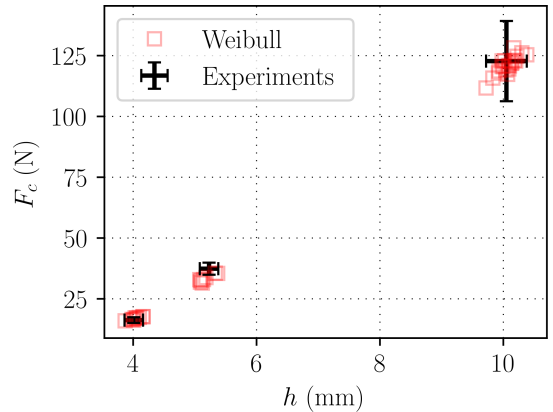

(a)

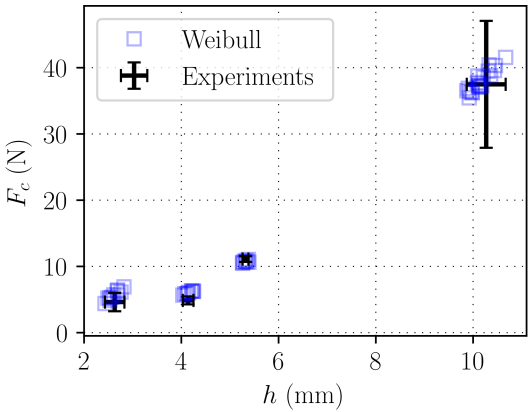

(b)

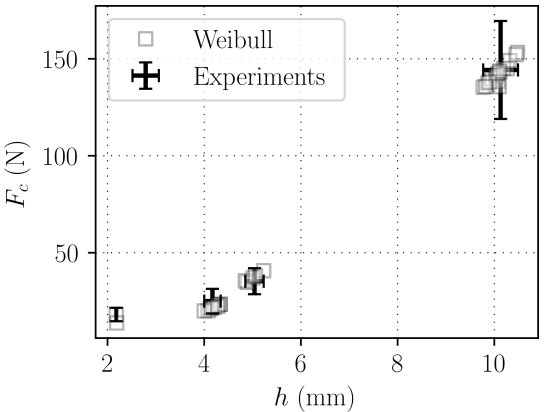

(c)

Figure 5: Failure forces obtained with Weibull's approach as a function of specimen width for a) $\alpha-$, b) $\beta-$ and c) $\gamma$ - gypsum. 


\begin{tabular}{|c|c|c|c|}
\hline & $\alpha$-gypsum & $\beta$-gypsum & $\gamma$-gypsum \\
\hline \hline$h(\mathrm{~mm})$ & $10.05 \pm 0.33$ & $10.27 \pm 0.4$ & $10.13 \pm 0.36$ \\
\hline Weibull & $5.8 \%$ & $11.5 \%$ & $6.5 \%$ \\
\hline CC & $6.5 \%$ & $12.8 \%$ & $8.3 \%$ \\
\hline \hline$h(\mathrm{~mm})$ & $5.23 \pm 0.15$ & $5.32 \pm 0.06$ & $5.04 \pm 0.19$ \\
\hline Weibull & $9.9 \%$ & $3.5 \%$ & $14.6 \%$ \\
\hline CC & $5.9 \%$ & $3.0 \%$ & $17.4 \%$ \\
\hline \hline$h(\mathrm{~mm})$ & $4.01 \pm 0.15$ & $4.14 \pm 0.11$ & $4.17 \pm 0.17$ \\
\hline Weibull & $5.3 \%$ & $24.6 \%$ & $8.5 \%$ \\
\hline CC & $4.3 \%$ & $6.5 \%$ & $9.2 \%$ \\
\hline \hline$h(\mathrm{~mm})$ & & $2.63 \pm 0.2$ & $2.18 \pm 0.01$ \\
\hline Weibull & & $19.0 \%$ & $13 . \%$ \\
\hline CC & & $10.0 \%$ & $4 . \%$ \\
\hline
\end{tabular}

Table 6: Mean difference between numerical predictions (CC or Weibull) and experimentally measured failure forces.

satisfying agreement with experimental data and allow traducing the size effect of increasing failure stress with decreasing specimen size. The mean relative difference between the failure forces measured experimentally and obtained using either Weibull's model or the CC are given in Tab 6. The mean relative difference between predictions and experimentally measured failure forces are in slight better agreement for small specimens with the $\mathrm{CC}$ than with Weibull's approach, especially for $\beta$-gyspum specimens. This can also be observed by studying the failure stress variation as a function of the specimen effective volume. According to Weibull's approach, the variation should follow a line with slope $-\frac{1}{m}$ in a log-log representation. The experimental data are shown as well as this line in Fig. 6. Whereas the size effect is well described for $\gamma$ - and $\alpha$-gypsum, it can be seen that for $\beta$-gypsum the prediction seems to slightly overestimate experimental data for the smallest specimens. This may be explained by analyzing the ratio between the specimen width and the material characteristic length for each gypsum type specimens. It results in ratios $\frac{h}{l_{\text {mat }}}$ between 3 and 15 and for $\gamma$-gypsum specimens, between 4 and 10 for $\alpha$-gypsum specimens and between 11 and 45 for $\beta$ - gypsum specimens. Therefore, a larger influence of specimen size on failure stress variation is theoretically expected for $\alpha$-gypsum and $\gamma$-gypsum than for $\beta$-gypsum specimens [26]. On the contrary, Weibull's approach predicts a larger size effect for $\beta$-gypsum that corresponds to the smallest Weibull's modulus value among the three gypsum types. Finally, for gypsum specimens, we can conclude that both the CC and Weibull's model are able to reproduce the failure stress or force variation as a function of the specimen size. 


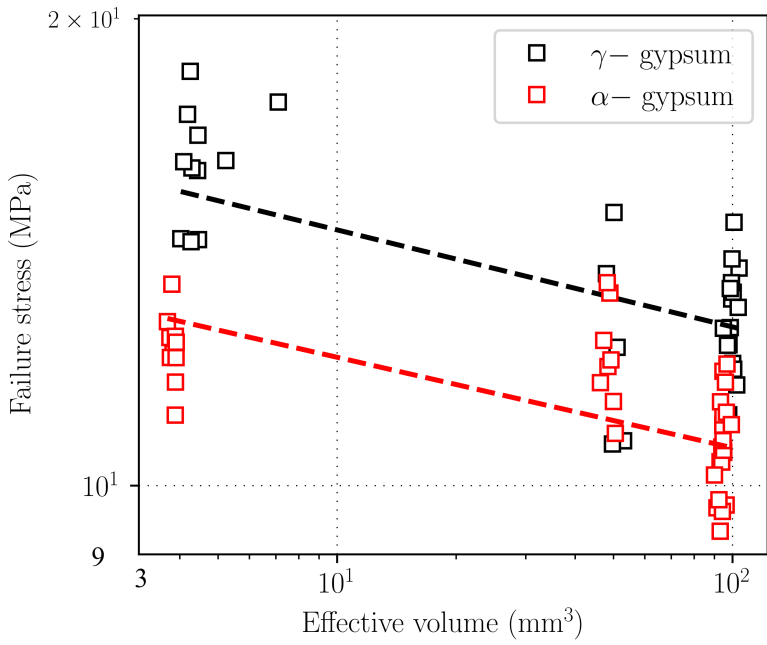

(a)



(b)

Figure 6: Failure stress as a function of the specimen effective volume for a) $\alpha$ - and $\gamma-$ and b) $\beta$ - gypsum specimens. The dashed line represent a line with slope $\left(-\frac{1}{m}\right)$.

\subsection{ZnO specimens}

The same approach as for gypsum specimens is followed for $\mathrm{ZnO}$ specimens tested in [8]. A $m=18.8$ Weibull's modulus is identified based on the set of smallest specimens following the procedure described in Section 4. Fig. 7 shows the failure stress and failure force measured experimentally and predicted using either the $\mathrm{CC}$ or Weibull's model as a function of the specimen effective volume. The CC allows a correct prediction of the failure stress variation whereas Weibull's approach underestimates the failure stress for the two sets of specimens for



(a)

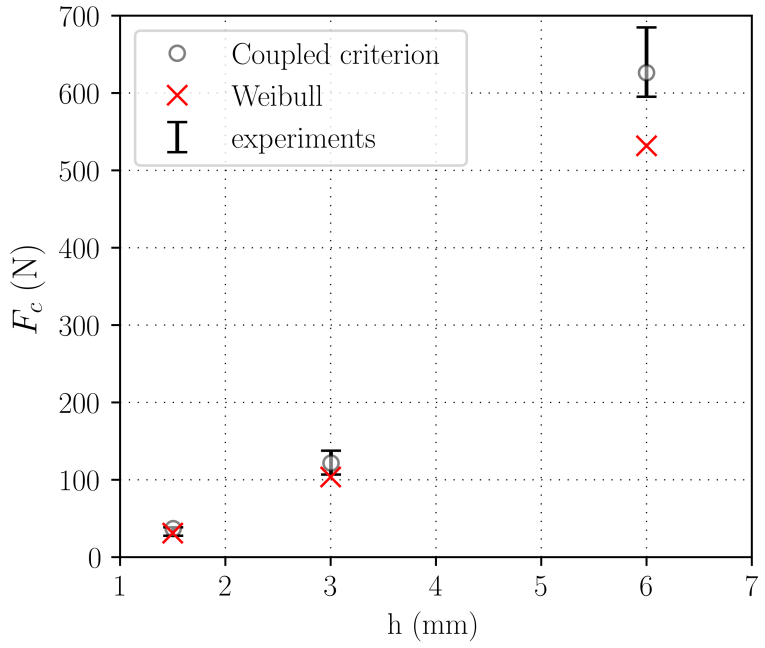

(b)

Figure 7: (a) Failure stress as a function of the specimen effective volume and b) failure force as a function of the specimen thickness for $\mathrm{ZnO}$ specimens. The dashed line in a) represent a line with slope $\left(-\frac{1}{m}\right)$. 
which blind predictions are performed. Actually, the studied set of specimens does not really exhibit a significant size effect of increasing failure stress with decreasing specimen effective volume, the failure stress being rather constant within the studied range of specimen size. Having a deeper look at the $\mathrm{CC}$ results, it appears that $l_{\text {mat }}=0.16 \mathrm{~mm}$ and the specimen

widths are $1.5 \mathrm{~mm}, 3.0 \mathrm{~mm}$ and $6.0 \mathrm{~mm}$ so that it results in ratios $\frac{h}{l_{m a t}}$ respectively around $9.4,18.8,37.5$. For such ratios, bending failure stresses close to the tensile strength $\sigma_{c}$ are expected (respectively $1.11 \sigma_{c}, 1.06 \sigma_{c}$ and $1.03 \sigma_{c}$ ) [26]. Therefore even if the CC predicts a size effect of increasing stress with decreasing specimen effective volume, this size effect remains moderate given the range of specimen width compared to material characteristic length.

Finally, contrary to the case of gypsum specimens for which both methods were able to reproduce the experimentally observed size effect, only the $\mathrm{CC}$ allows a correct description of the failure stress variation as a function of the specimen effective volume. Two explanations may be provided based either on the $\mathrm{CC}$ or the Weibull's approach point of view. The first explanation, based on the $\mathrm{CC}$, is that for specimens sufficiently large with respect to the material characteristic length, no size effect or only a slight variation of the failure stress as a function of the specimen size is expected. The second explanation, related to Weibull's approach assumption, relies on considerations about the material microstructures. Diffused porosity in gypsum specimens is mainly of the micrometer size but there are also some isolated macropores arising from manufacturing, thus following Weibull's approach assumptions. On the contrary, $\mathrm{ZnO}$ specimens contain a large number of flaws gathering into groups and interacting between them [11], so that the Weibull's approach assumption of failure being controled by one (the largest) flaw may not be verified.

\section{Failure induced by a critical pore}

In this section, we study the influence of a single pore on crack initiation and especially the relation between the characteristics of the pore (size and location) and the corresponding variation of the failure force. 


\subsection{Crack initiation in presence of a pore}

We first study which of the three scenarii given in section 4.3 is more likely to trigger crack initiation in the specimen containing a pore. The most critical scenario is determined as the one minimizing the failure loading predicted by the coupled criterion. We recall that it requires both the stress and the energy conditions given in Eq. (6) to be simultaneously satisfied. We therefore analyze i) the stress along the crack path and ii) the incremental energy release rate variation as a function of the crack length in the three cases. They are shown in Fig. 8 as a matter of example for a pore with the following characteristics: $\frac{h_{d}}{h}=0.15$ and $\frac{d}{h}=0.09$ ( $c f$. Fig. 3 for the definition of the geometry parameters). The stress variation as a function of the distance to the specimen edge under tension $\frac{y}{h}$ is shown in Fig. 8 a. The pore induces two stress concentrations at the two hole tips which magnitudes are larger than that of the stress level at the specimen edge under tension. It results in the following stress variations (prior to crack initiation) as a function of the crack length for the three possible scenarii (Fig. 8b):

case 1) The stress is a decreasing function of the crack length on the ligament between the hole and the specimen edge under tension. It also decreases again for crack lengths larger than the ligament length, starting for a value larger than the minimum stress attained over the ligament so that its overal variation is non-monotonic.
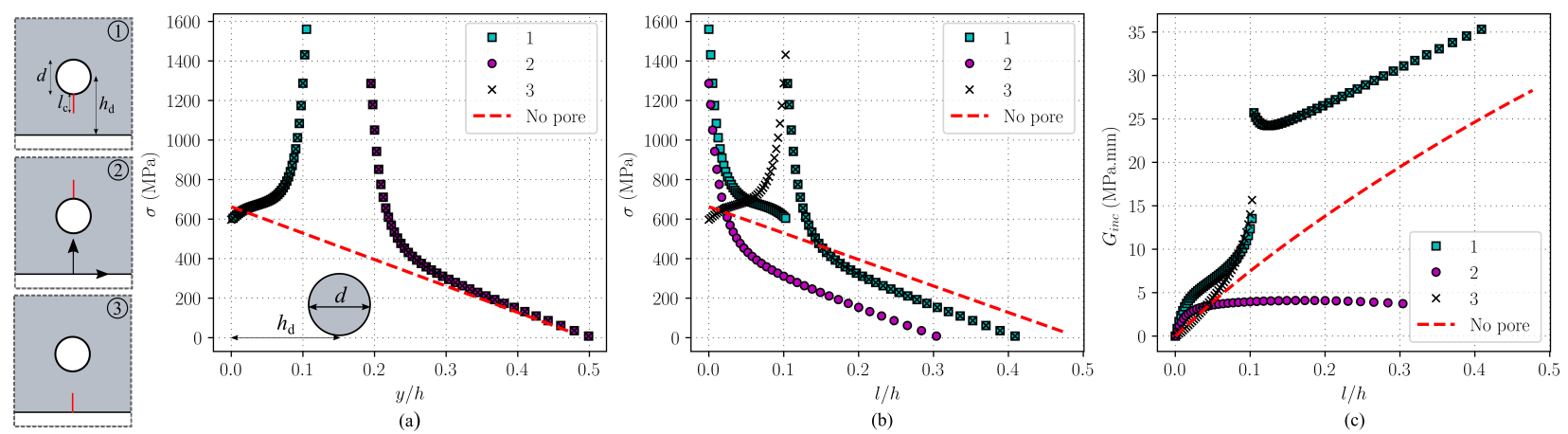

Figure 8: a-b) Stress along the specimen middle plane for a $1 \mathrm{~mm}$ applied displacement at the upper spans as a function of a) the normalized distance to the specimen edge under tension or b) the normalized crack length; c) Incremental energy release rate as a function crack lengths for the three studied crack initiation scenarii and the case without a pore. Illustration of the results for $h_{d}=0.15 h$ and $d=0.09 h$. The three investigated scenarii are recalled on the left part of the figure. 
case 2) The stress exhibits a monotonically decreasing variation as a function of the crack length.

case 3) The stress is increasing over the ligament and then decreasing for crack lengths larger than the ligament length.

Fig. 8p shows the incremental energy release rate variation as a function of the normalized crack length, which variation is monotonically increasing for the three studied scenarii. For a given crack length, both the incremental energy release rate and the stress magnitudes are smaller for scenario 2 than for scenario 1. It means that a larger loading level is necessary in order to fulfill simulatenously both criteria for scenario 2 , which is thus unlikely to happen. For crack lengths larger than the ligament lengths, scenarii 1 and 3 yield the same results due to similar stress and incremental energy release rate variations. Reminding that the stress criterion states that the stress must be larger than the strength all over the initiation crack path, it yields that for scenario 3, the initiation crack length cannot be smaller than the ligament length. Indeed, if the stress criterion is reached for a crack length $l<h_{d}$, it is also reached for a crack length $l=h_{d}$ because of the increasing stress variation as a function of the crack length. Moreover, the incremental energy release rate for scenario 3 is smaller than for scenario 1 for a given crack length smaller than the ligament length. We thus conclude that for this first example $\left(h_{d}=0.15 h\right.$ and $\left.d=0.09 h\right)$, crack initiation occurs starting from the hole on the side of the specimen edge under tension (scenario 1).

Crack initiation length is not known a priori, it is an output of the coupled criterion that is determined solving Eqs. (66). It is, however, related to $l_{\text {mat }}$ [34]. Depending on $l_{\text {mat }}$ value with respect to $h_{d}$ and $d$, two cases may be distinguished: if $l_{\text {mat }}$ is large enough, then crack initiation length is larger than $h_{d}+\frac{d}{2}$, which means that at initiation the crack jumps quasi-instantaneously over the hole (Fig. 9a). Otherwise, if $l_{m a t}$ is small enough, then crack initiation occurs within the ligament between the hole and the specimen edge under tension (Fig. 9b). In both cases, crack initiation is likely to be immediately followed by unstable propagation, so that crack initiation and subsequent propagation steps cannot be distinguished experimentally.

The same analysis as previously is presented for a smaller pore, close to the specimen center, 


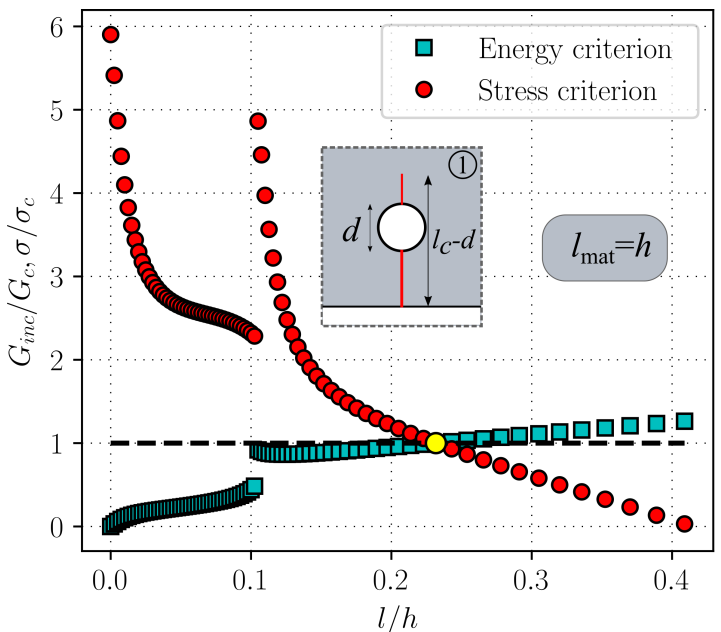

(a)

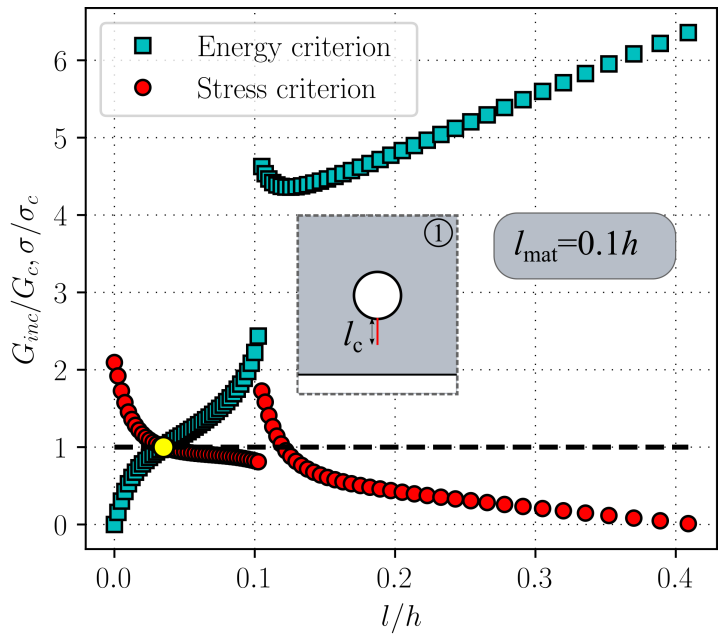

(b)

Figure 9: Incremental energy release rate to fracture toughness and stress to strength ratios as a function of the normalized crack length for initiation lengths a) large $\left(l_{\text {mat }}=h\right)$ and b) small $\left(l_{\text {mat }}=0.1 h\right)$ with respect to the ligament length (Scenario 1). Yellow circles represent the normalized initiation crack length.

with the following characteristics: $\frac{h_{d}}{h}=0.25$ and $\frac{d}{h}=\frac{1}{40}$. The stress variation as a function of the distance to the specimen edge under tension $\frac{y}{h}$ is shown in Fig. 10a. As noticed in the previous case, the pore induces two stress concentrations at the two hole tips in addition to the stress concentration at the specimen edge under tension. It results in the following stress variations as a function of the crack length for the three possible scenarii (Fig. 10b):

case 1) The stress is a decreasing then increasing function of the crack length on the ligament between the hole and the specimen edge under tension. It also decreases again for crack lengths larger than the ligament length, starting for a value larger than the minimum
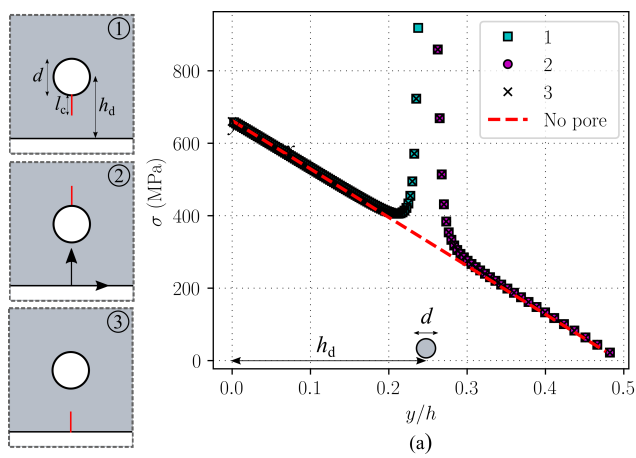

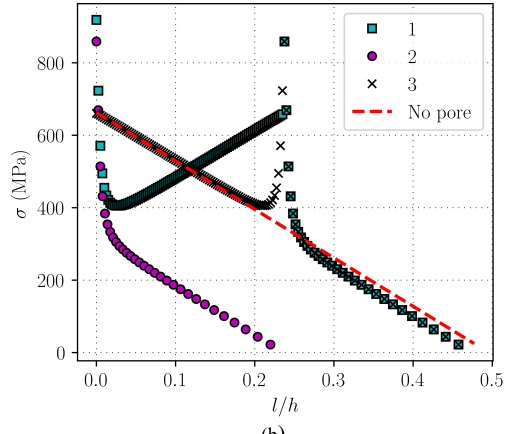

(b)

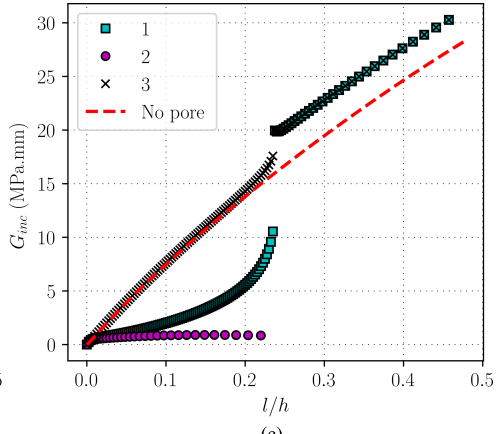

(c)

Figure 10: a-b) Stress along the specimen middle plane for a $1 \mathrm{~mm}$ applied displacement at the upper spans as a function of a) the normalized distance to the specimen edge under tension or b) the normalized crack length; c) Incremental energy release rate as a function crack lengths for the three studied crack initiation scenarii and the case without a pore. Illustration of the results obtained for $h_{d}=0.25 h$ and $d=h / 40$. The three investigated scenarii are recalled on the left part of the figure. 
stress attained over the ligament so that its overal variation is non-monotonic.

case 2) The stress exhibits a monotonically decreasing variation as a function of the crack length.

case 3) The stress is a decreasing then increasing function of the crack length on the ligament between the specimen edge under tension and the hole. It decreases for crack lengths larger than the ligament length, starting for a value larger than the minimum stress attained over the ligament so that its overal variation is non-monotonic.

Fig. 10c shows the incremental energy release rate variation as a function of the normalized crack length, which variation is monotonically increasing for the three studied scenarii. For a given crack length, both the incremental energy release rate and the stress magnitudes are smaller for scenario 2 than for scenarii 1 and 3. It means that a larger loading level is necessary in order to fulfill simulatenously both criteria for scenario 2, which is therefore unlikely to happen. As noted previously, for crack lengths larger than the ligament lengths, scenarii 1 and 3 yield the same results due to similar stress and incremental energy release rate variations. For a given value of crack length, the incremental energy release rate is smaller for scenario 1 than for scenario 3, so is the stress except for small crack lengths. We thus conclude that for this first example, crack initiation occurs starting from the specimen edge under tension (scenario 3).

If $l_{\text {mat }}$ is large enough, then crack initiation length is larger than $h_{d}+\frac{d}{2}$, which means that at initiation the crack jumps quasi-instantaneously over the hole (Fig. 11a). For sufficiently small $l_{\text {mat }}$ for which crack initiation length is smaller than $h_{d}+\frac{d}{2}$, crack initiation occurs within the ligament between the specimen edge under tension and the hole. In both cases, unstable crack propagation follows crack initiation.

Finally, two crack initiation scenarii are likely to happen:

- Crack initiating from the hole, on the side of the specimen edge under tension. This initiation configuration is likely for sufficiently small ligament size $h_{d}-\frac{d}{2}$.

- Crack initiating from the specimen edge under tension. This initiation configuration 


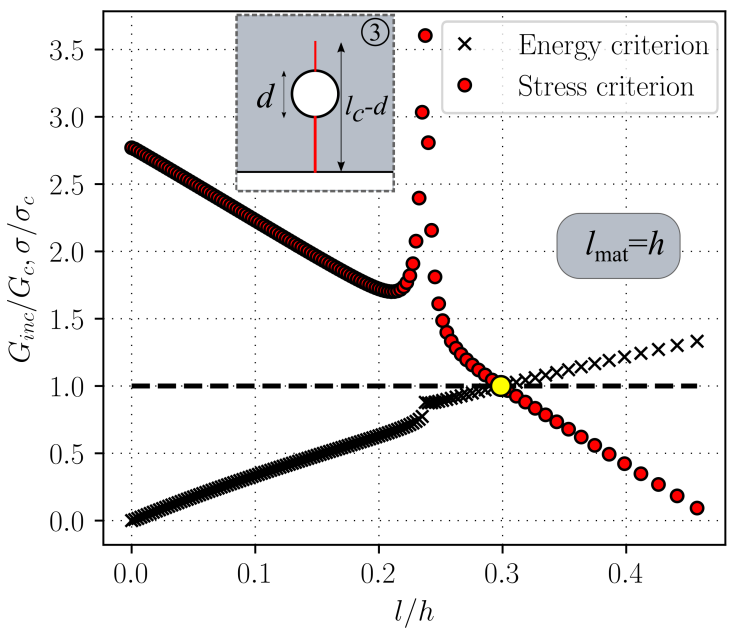

(a)

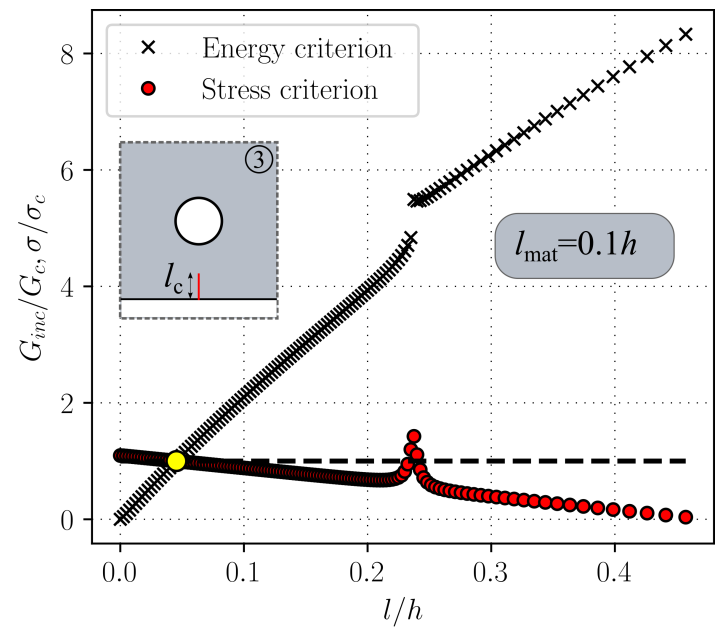

(b)

Figure 11: Incremental energy release rate to fracture toughness and stress to strength ratios as a function of the normalized crack length for initiation lengths a) large $\left(l_{\text {mat }}=h\right)$ and b) small $\left(l_{\text {mat }}=0.1 h\right)$ with respect to the ligament length (Scenario 3).

is likely if the pore is sufficiently far from the specimen edge under tension (for large enough $h_{d}-\frac{d}{2}$ )

In both cases crack initiation is followed by unstable crack propagation so that experimentally we cannot distinguish crack initiation from crack propagation steps, the specimen failure occurs quasi-instantaneously after crack initiation. Moreover, it can be noted that the failure force in presence of a pore is always smaller or equal to the failure force without a pore, the $\mathrm{CC}$ allows quantifying this force decrease due to the pore.

\subsection{Determination of critical pore size}

As observed in Fig. 4, the CC predictions are close to the experimental measurements but there is still some discrepancy between numerical and experimental failure forces. A possible explanation is that we did not take into account the possible presence of a critical pore triggering failure in the simulations. In previous section we showed the ability of the CC to predict for given pore location and diameter the failure force and therefore the failure force decrease due to the pore compared to the case without pore. In this section we use these results to characterize the critical pore size in the tested gypsum specimens considering, as for Weibull's analysis, that failure may be due to the presence of a critical pore. The same assumptions as previously are made, i.e. that the pore is located within the specimen 
area under tension and that it entirely lies within the specimen. The presence of a pore is expected to result in a decrease in the failure force $\left(F_{c}=F_{c}\left(h_{d}, d\right)\right)$ compared to the failure force $\left(F_{c}^{r e f}\right)$ corresponding to the same configuration without a pore. We can thus define a force decrease ratio $\left(\frac{F_{c}}{F_{c}^{\text {ref }}}\right)$ corresponding to a given pore diameter $(d)$ and location (distance to the specimen edge under tension $h_{d}$ ).

Fig. 12 shows the force decrease ratio for several distances of the pore center to the specimen edge. Since we do not consider surface flaws, for a given $h_{d}$ the maximum pore size is $\frac{h_{d}}{2}$. Our objective is to estimate the critical pore size given the failure force decrease ratios measured experimentally. It can be observed that several pore configurations (pore diameter and location) lead to the same failure force decrease ratio (Fig. 12a). Therefore we cannot determine a unique pore diameter and location couple corresponding to a given failure force decrease ratio. However, from these curves we can deduce an envelope of the force decrease

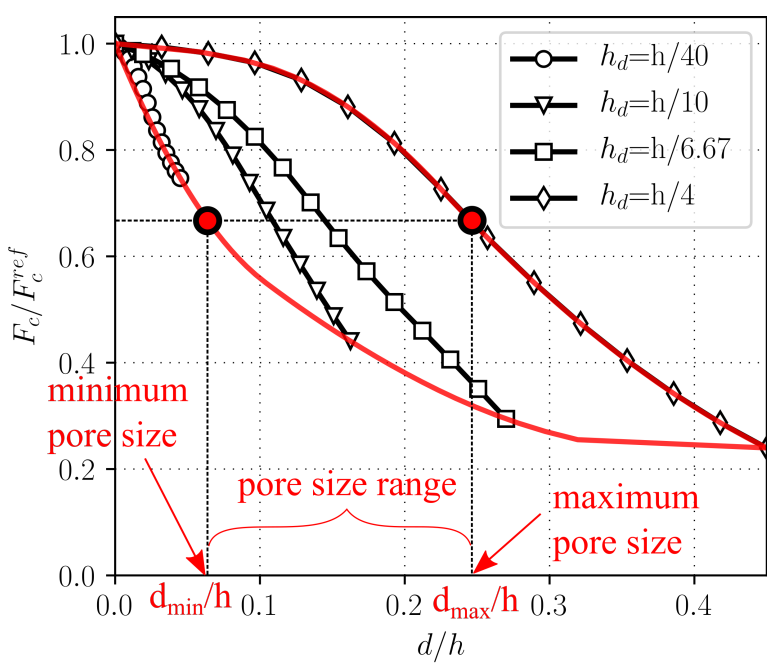

(a)

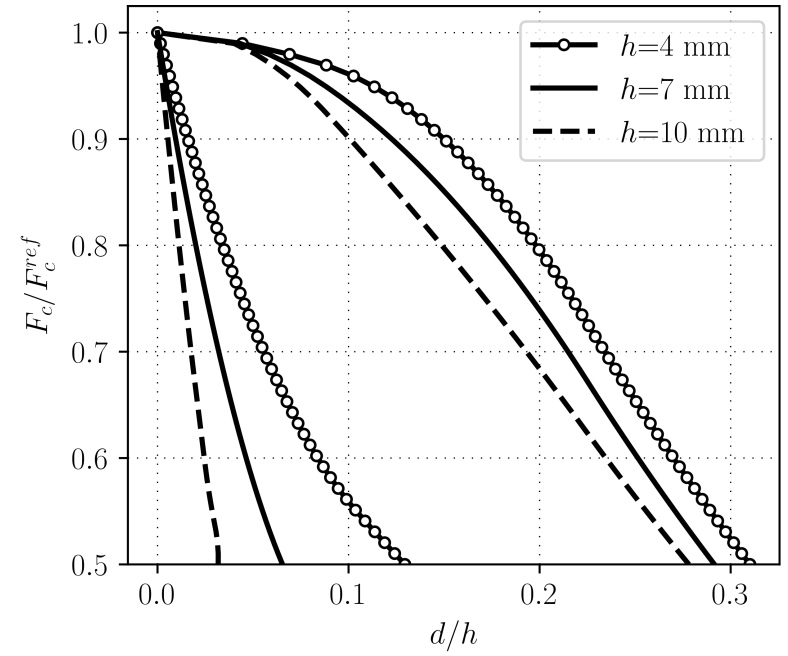

(b)

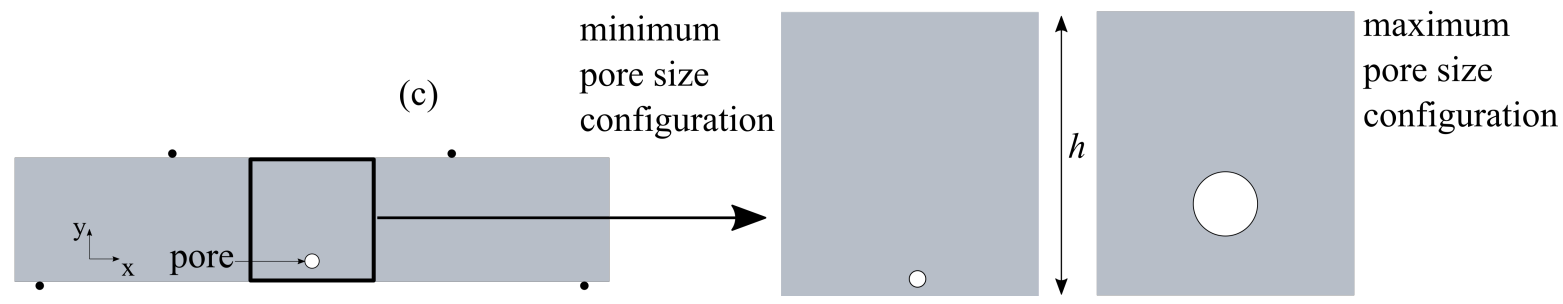

Figure 12: Failure force decrease ratio as a function of the normalized pore diameter obtained for several pore distance to the specimen edge under tension. a) Minimum and maximum critical pore size determination as the envelope of the curves and b) influence of the specimen size on the failure force decrease ratio envelope variation. (c) Configurations corresponding to minimum and maximum pore size determined from (a). 
ratio which can be used in the following way: for a given $\frac{F_{c}}{F_{c}^{r e f}}$, we determined the minimum $\left(d_{\min }\right)$ and maximum $\left(d_{\max }\right)$ pore size that lead to such a force decrease (Fig. 12a). All the intermediate pore diameters between $d_{\min }$ and $d_{\max }$ are also admissible, corresponding to different pore locations in the specimen width $h_{d}$. It can be noted that the failure force decrease ratio envelope depends on both the specimen width $h$ (cf. Fig. 12b) and on the material characteristic length $l_{\text {mat }}$. However, similar envelopes and therefore similar $d_{\text {min }}$ and $d_{\text {max }}$ values are obtained for any $\left(h, l_{\text {mat }}\right)$ couple leading to the same $h / l_{\text {mat }}$ ratio.

Fig. 13 shows the minimum and maximum pore size determined based on the measured force decrease ratios for the three types of gypsum specimens as a function of their density (Fig. 13a) and their width (Fig. 13b). The same specimen widths $h$ as in the experiments were used in the model to compute the pore size ranges. Reminding that all the pore diameters between the determined minimum and maximum pore size are possible critical pore sizes (corresponding to different pore locations within the specimen width), the estimated order of magnitude of the critical pore sizes are is in the range 50-250 microns. This order of magnitude is consistent with experimental observations [35] of gypsum specimen fracture surfaces (Fig. 11). Several pore sizes and locations are observed on the fracture surfaces, which may be more or less critical depending not only on their size but also on their position with respect to the face undergoing tension. In some cases, a cluster of several porosities

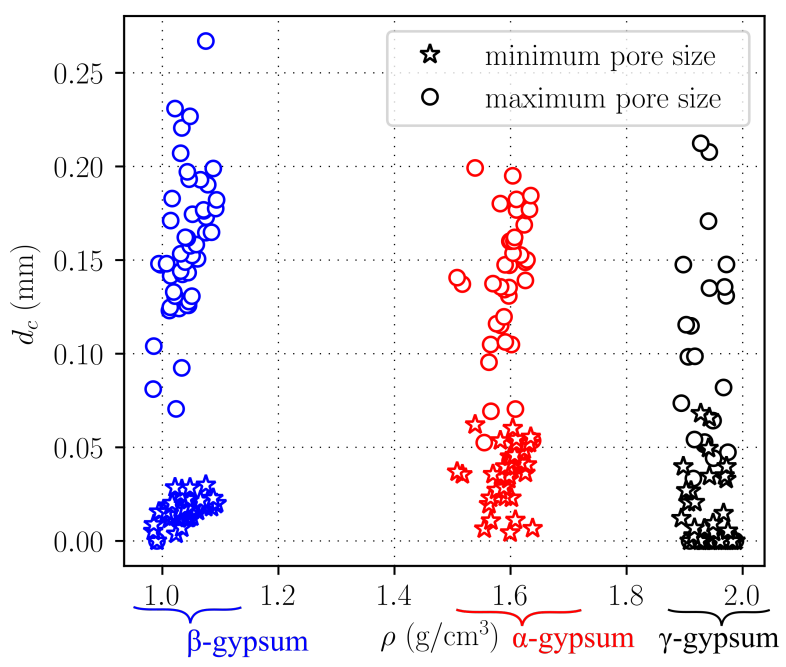

(a)



(b)

Figure 13: Critical pore diameter $\left(d_{c}\right)$ ranges for $\alpha-\beta-$ and $\gamma-$ gypsum specimens as a function of (a) gypsum density or (b) specimen width. 
may also be observed, which was not taken into account in the model. It can be observed that similar order of magnitudes are obtained for the three types of gypsum even if they exhibit different densities and pore fractions. A critical pore is much larger than the gypsum mean pore size which depends on the quantity of water required for manufacturing. Gypsum is processed by mixing of hemihydrate powder with water leading to an hydration reaction and to the formation of entangled needle-shaped crystals. The porosity in the final material is mainly of the micrometer size (interconnected pores betwen the gypsum crystals) and macropores originating from entrapped air in the hemidrate powder before mixing [36, 37]. The presence of entrapped air in the slurry, that will lead to macropores in the material after hydration and drying, is mainly controlled by the rheology of the slurry. For the three types of gypsum considered in this work, the amount of water for mixing was adapted to have a similar rheology of the slurry. The water on solid ratio used decreases for the processing of gamma, alpha and beta gypsum respectively, leading to different relative densities (see Tab. 1). Therefore, the characteristics of the macro porosity (number and diameter of pores) depend mainly on the paste rheology which is similar between the three types of gypsum,

which gives an explanation to the similar estimated order of magnitude for the critical pore size in the different specimens.

It can also be observed that the maximum possible critical pore size is slightly increasing with decreasing specimen size: from around 50-150 microns for the largest specimens to around 50-250 microns for the smallest specimens. It may be related to the fact that larger relative scattering and uncertainty is obtained for smaller specimen [26]. Morever, we remind that $d_{\min }$ and $d_{\max }$ are only bounds to estimate a critical pore size that may be any values in between. It can thus be concluded that a similar order of magnitude of critical pore size is obtained whatever the specimen size. This result questions the basis assumption of Weibull's analysis that the larger the specimen, the larger the critical flaw triggering failure.

\section{Conclusion}

Both Weibull's approach and the coupled criterion allow reproducing size effects of decreasing bending failure stress with increasing specimen size in several types of gypsum specimens. Whereas the latter also succeeds in predicting the failure stress variation as a 
function of the effective volume of $\mathrm{ZnO}$ specimens, the former leads to a severe deviation from the experimental results. It may be explained either based on the $\mathrm{CC}$ that predict no (or limited) size effect for the range of specimen sizes, or based on considerations about failure not being driven by a single critical flaw but depending on possible interaction between several flaws. We also show that the Weibull's model assumption of larger critical flaws in larger specimen may not hold true. Employing the same reasoning as Weibull's approach that failure is driven by the most critical flaw in the area sollicitated under tension, we simulate crack initiation due to a critical pore using the coupled criterion. It results in a decrease of the failure force with respect to the same configuration without a pore. This failure force decrease can be associated with a range of pore size corresponding to several positions within the specimen width. Based on the failure force measured experimentally, we thus estimate the possible critical pore size ranges for the different gypsum types. A similar order of magnitude around 50-250 microns is obtained for the three gypsum types. Moreover, we do not retrieve increasing critical pore size with increasing specimen size, as assumed in Weibull's approach, but rather a constant critical pore size range for all specimens.

\section{References}

[1] Z. Bažant, Size effect on structural strength: a review, Archive of applied Mechanics 69 (9-10) (1999) 703-725.

[2] Z. Bažant, Size effect in blunt fracture: concrete, rock, metal, ASCE J Engrg Mech 110 (1984) 518-35.

[3] Z. Bažant, P. Pfeiffer, Determination of fracture energy from size effect and brittleness number, ACI Materials J. 84 (1987) 463-480.

[4] Z. Bažant, Y. Xi, Statistical size effect in quasi-brittle structures: Ii. nonlocal theory, ASCE J. Eng. Mech. 117(11) (1991) 2623-2640.

[5] W. Weibull, The phenomenon of rupture in solids, Proc. Royal Swedish Inst. Eng. Res. 153 (1939) 1-55. 
[6] W. Weibull, A statistical representation of fatigue failures in solids., Proc. Roy. Inst. Techn. 27 (1949).

[7] W. Weibull, A statistical distribution function of wide applicability, J. Appl. Mech. ASME 18 (1951).

[8] C. Lu, R. Danzer, F. Fischer, Scaling of fracture strength in zno: Effects of pore/grain size interaction and porosity, J. Eur. Cer. Soc. 24 (2004) 3643-3651.

[9] R. Danzer, R. Supancic, J. Pascual, T. Lube, Fracture statistics of ceramics - weibull statistics and deviations from weibull statistics, Engng. Fract. Mech. 74 (2007) 29192932.

[10] P. Bermejo, R. Supancic, R. Danzer, Influence of measurement uncertainties on the determination of the weibull distribution, J. Eur. Cer. Soc. 32 (2012) 251-255.

[11] C. Lu, R. Danzer, F. Fischer, Fracture statistics of brittle materials: Weibull or normal distribution, Phys. Rev. E 65 (2002) 067102.

[12] Z. Bažant, J. Planas, Fracture and size effect in concrete and other quasibrittle materials, Boca Raton: CRC Press, 1998.

[13] D. Leguillon, Strength or toughness? a criterion for crack onset at a notch, Eur. J. Mech. - A/Solids 21(1) (2002) 61-72.

[14] I. G. García, B. J. Carter, A. R. Ingraffea, V. Mantič, A numerical study of transverse cracking in cross-ply laminates by 3d finite fracture mechanics, Compos. Part B 95 (2016) 475-487.

[15] I. G. García, V. Mantič, A. Blázquez, The effect of residual thermal stresses on transverse cracking in cross-ply laminates: an application of the coupled criterion of the finite fracture mechanics, Int. J. Fract. 211 (2018) 61-74.

[16] I. García, J. Justo, A. Simon, V. Mantič, Experimental study of the size effect on transverse cracking in cross-ply laminates and comparison with the main theoretical models, Mech. of Mat. 128 (2019) 24-37. 
[17] P. Cornetti, N. Pugno, A. Carpinteri, D. Taylor, Finite fracture mechanics: A coupled stress and energy failure criterion, Engng. Fract. Mech. 73 (2006) 2021-2033.

[18] D. Leguillon, D. Quesada, C. Putot, E. Martin, Size effects for crack initiation at blunt notches or cavities, Engng. Fract. Mech. 74 (2007) 2420-2436.

[19] A. Carpinteri, P. Cornetti, A. Sapora, Brittle failures at rounded v-notches: a finite fracture mechanics approach, Int. J. Fract. 172 (2011) 1-8.

[20] P. Cornetti, A. Sapora, A. Carpinteri, Mode mixity and size effect in v-notched structures, Int. J. Sol. Struct. 50(10) (2013) 1562-1582.

[21] A. Doitrand, R. Estevez, D. Leguillon, Experimental characterization and numerical modeling of crack initiation in rhombus hole pmma specimens under compression, Eur. J. Mech. Sol. 76 (2019) 290-299.

[22] E. Martin, D. Leguillon, N. Carrère, A coupled strength and toughness criterion for the prediction of the open hole tensile strength of a composite plate, Int. J. Sol. Struct. 49(26) (2012) 3915-3922.

[23] P. Cornetti, A. Sapora, Penny-shaped cracks by finite fracture mechanics, Int. J. Fract. 219 (2019) 153-159.

[24] A. Doitrand, A. Sapora, Nonlinear implementation of Finite Fracture Mecahnics: A case study on notched Brazilian disk samples, Int. J. Non-Linear Mech. 119 (2020) 103245.

[25] D. Leguillon, E. Martin, M. Lafarie-Frenot, Flexural vs. tensile strength in brittle materials, Comptes Rendus Mecanique 343 (2015) 275-281.

[26] A. Doitrand, R. Henry, S. Meille, Strength and fracture toughness estimation from fourpoint bending test, J. Theor. Comp. App. Mech. (2021). doi:https://doi.org/10. 46298/jtcam.6753.

[27] S. Meille, E. Garboczi, Linear elastic properties of 2d and 3d models of porous materials made from elongated objects, Model. Simul. Mater. Sci. Engng. 9 (2001) 371-390. 
[28] S. Meille, Etude du comportement mécanique du plâtre pris en relation avec sa microstructure, Thèse de doctorat, Institut National des Sciences Appliquées de Lyon (2001).

[29] J. Sanahuja, L. Dormieux, S. Meille, C. Hellmich, A. Fritsch, Micromechanical explanation of elasticity and strength of gypsum: from elongated anisotropic crystals to isotropic porous polycrystals., J. Engng. Mech. 136 (2010) 239-253.

[30] H. Yoshimura, A. Molisani, N. Narita, J. Manholetti, J. Cavenaghi, Mechanical properties and microstructure of zinc oxide varistor ceramics, Materials Science Forum 530-531 (2006) 408-413.

[31] A. Doitrand, E. Martin, D. Leguillon, Numerical implementation of the coupled criterion: Matched asymptotic and full finite element approaches, Fin. Elem. Anal. Des. 168 (2020) 103344.

[32] A. Doitrand, R. Henry, I. Zacharie-Aubrun, G. J.M., S. Meille, $\mathrm{Uo}_{2}$ micron scale specimen fracture : Parameter identification and influence of porosities, Theor. Appl. Fract. Mech. 108 (2020) 102665.

[33] A. Doitrand, D. Leguillon, Comparison between 2D and 3D applications of the coupled criterion to crack initiation prediction in scarf adhesive joints, Int. J. Adh. Adh. 85 (2018) 69-76.

[34] E. Martin, D. Leguillon, O. Seveček, R. Bermejo, Understanding the tensile strength of ceramics in the presence of small critical flaws, Engng. Fract. Mech. 201 (2018) 167-175.

[35] J. Adrien, S. Meille, S. Tadier, E. Maire, L. Sasaki, In-situ x-ray tomographic monitoring of gypsum plaster setting, Cement and Concrete Research 82 (2016) 107-116.

[36] J. Devillard, J. Adrien, S. Roux, S. Meille, E. Maire, Highlighting the role of heterogeneity on the indentation hardness of foamed gypsum, J. Eur. Cer. Soc. 40 (11) (2020) $3795-3805$.

[37] S. Meille, M. Saadaoui, P. Reynaud, G. Fantozzi, Mechanisms of crack propagation in dry plaster, J. Eur. Cer. Soc. 23 (20003) 3105-3112. 